\title{
Analyses the Driving Forces for Urban Growth by Using IDRISI®Selva Models Abouelreesh — Aswan as a Case Study
}

\author{
Omar Hamdy, Shichen Zhao, Mohamed A. Salheen, and Y. Y. Eid
}

\begin{abstract}
Urban growth is very dynamic and complex processes, It has many factors affects on the directions and value of urban extensions, the factors that drive urban development must be identified and analyzed, The study of relative research shows that the driving forces which lead and redirect the urban sprawl, and try to classified these driving forces based on the value of its effectives on urban growth, Achieving the classification of driving forces needs using statistical method, our study used the logistic regressions to analysis and classes the driving forces for urban sprawl, Identifying the driving forces is the most important step to prediction the urban growth in future by using the cellular automata models so that the research try to prepare this step to complete the procedure to expect the urban extensions, This study takes Aswan area as a case study in period from 2001 to 2013 by analysis the official detailed plan and google earth historical imagery, Almost data prepared to logistic regressions analysis using ArcGIS software and IDRISI ${ }$ Selva. We studied historical imagery of the area using Google Earth to examine changes in urban growth in 2001 and 2013, over a span of 12 years. The results showed urbanization in risk areas to be $59.79 \%$ in 2001 , then rising to $65.45 \%$ in 2013 , by the end of this paper it can be classified the effect of the driving forces in study area.
\end{abstract}

Index Terms-Driving forces, urban growth, IDRISI ${ }$ Selva, Aswan.

\section{INTRODUCTION}

\section{A. Urban Sprawl}

City landscapes have been rapidly changing in the last few decades in response to accelerated population growth and the transition from rural to urban areas. [1] According to United Nations projections, urban population will increase by 1.35 billion by 2030, at which time the urban population in the world will be approximately 5 billion. It is forecast that global urban land will increase by 1.2 million $\mathrm{km} 2$ by 2030 , which will be almost triple the global urban land area circa 2000 [2].

Manuscript received January 5, 2016; revised April 4, 2016. This work was supported in part by the Egyptian Cultural Affairs \& Missions Sector, Egypt and financial grant from Kyushu University, Japan.

Omar Hamdy is with Graduate School of Human-Environment Studies Department of Architecture and Urban Design, Fukuoka, Japan. And Faculty of Engineering Architectural Engineering Department, Aswan, Egypt (e-mail: OMARGEM56@yahoo.com).

Shichen Zhao is with Graduate School of Human-Environment Studies Department of Architecture and Urban Design, Fukuoka, Japan (e-mail: zhao@arch.kyushu-u.ac.jp).

Mohamed A. Salheen and Y. Y. Eid are with Faculty of Engineering, Architectural Engineering Department, Ain Shams University, Cairo, Egypt.
Urban growth usually leads to changes in land use and land cover in many areas around the world, especially in developing countries. [3] Moreover, urban areas have a natural extension in multiple directions, sometimes with growth even heading towards places prone to natural disasters. Hence, decision-makers and planners should mitigate this problem through risk management and by providing different alternatives.

Urban sprawl, a serious problem for many rapidly developing countries, refers to the uncontrolled growth of an urban area resulting from poorly or totally unplanned urbanization [4]. An indicator of urban growth in terms of growth rate and growth direction, urban sprawl is also a type of low-density development with residential, shopping, and office areas. In fact, any form of suburban growth should be counted as urban sprawl [5]. Urban sprawl is today one of the most widely discussed issues in urban studies [6]. The encroachment of urban land uses on nonurban land has become a common phenomenon throughout developing countries, and its impact has attracted increasing attention from planners and policy makers [5].

By the 1970s, urban sprawl was not only seen as an inefficient pattern of urbanization but also as a phenomenon that damaged inner cities, and therefore it had to be brought under stricter control [7]. The beginning of the 21 st century saw urban population reaching a milestone when census showed that half of the world's population resided in cities [2]. Like many developing countries, Egypt has to grapple with the problems caused by urban sprawl. For the past five decades, there has been an unprecedented urbanization process despite the government's efforts to slow it down. While only less than $10 \%$ of the present total population lived in towns and cities at the beginning of the 20th century, the urban population rose by $45 \%$ by the end of the century. The annual growth rate of the urban population is projected at 2.2 percent until 2050, exceeding the 1.8 percent annual growth rate of the entire population [8]. Urban population growth is a worldwide phenomenon but the rate of urbanization is especially fast in Egypt.

The phenomenon is mainly driven by unorganized expansion, increased immigration, and rapidly increasing birth rate [9]. Coupled with unplanned developmental activities, this has resulted in the growth of many new urban areas that lack adequate infrastructure facilities [9]. Determining the trend and the rate of urbanization is vital to the establishment of rational land use policies [10].

\section{B. Google Earth High Resolution Imagery}

While some scientists have recently begun using this rapidly expanding, cost-free imagery source, the Google 
Earth high-resolution imagery archive remains a largely unexploited resource for the scientific analysis and description of the Earth's land surface [11]. Google Earth is an important development for the science community as it opens a trove of free geo-referenced, high resolution images that continue to improve with increased spatial and temporal depths [12]. Most high resolution imagery available in GE is concentrated around urban areas, roads, rivers, and areas of economic interest [12]. Imagery at these resolutions allows observers to readily discriminate between major natural land cover classes, and to discern components of the built environment, such as individual houses, industrial facilities, and roads [11].

Google Earth provides a powerful tool for viewing global imagery with integrated GIS data, maps, and graphics, e.g. identifying borders and roads, placing labels, zooming in/out, and viewing historical archived data among other tools [13]. One exciting way is to look at changes in land cover over time. Historical Imagery is a new map display option in Google Earth 5.0 [14]. Moreover, a new capability of the GE plug-in (v6) is access to historical imagery with a time slider [12]. Although Google Earth provides historical imagery of almost an endless number of sites around the world, the United Nations' paired imagery is particularly useful for this exercise because it has been selected to represent a variety of causes of landscape change [15]. Google Earth now hosts high-resolution ( $<2.5$ meter) imagery from 2000 to 2010, with most images being from 2003 to 2007 [11], [12].

Google Earth high resolution imagery offers many important features for land-use/land-cover (LULC) mapping in that they: (1) are free for non-profit use, (2) stream quickly to the web browser from Google's server, even with relatively slow Internet connections, (3) have sufficient spatial and color details to distinguish basic LULC classes at multiple spatial scales, (4) are georeferenced with sufficient accuracy for LULC mapping, (5) are distributed across the globe and cover a wide range of LULC classes, including those that are relatively small areas of the landscape, and (6) range in date from 2000 to the present, allowing temporal sampling [12].

Manual photointerpretation has the advantage of identifying real world objects rather than the image objects extracted in object-based classification approaches. The image interpreter may be better able to identify and to discriminate between real world objects based on context, relationships to neighboring objects, and complex variations in tone, color, and pattern [16]. Several recent studies have used visual interpretation of high resolution imagery in the GE desktop application to provide low-cost and reasonably accurate reference data, both for producing land-cover maps and testing their accuracy [12]. Despite advances in automated and semi-automated classification such as geographic object-based image analysis, manual photointerpretation still remains, to a good extent, the method of choice for producing fine-scale forest and landcover maps that cannot be made in automated extraction [16]. It is strongly recommended to consult the Google Earth historical imagery to help determine the feasibility of studies on coastal landscape dynamics [17]. It may be the only suitable strategy for identifying such diverse and fine- scale urban land use as urban agriculture, particularly on the scale of the home garden [16].

\section{Driving Forces}

Understanding the driving mechanisms of urban land spatial expansion (ULSE) is crucial for the guidance of rational urban land expansion, it is necessary to develop effective planning and management strategies, and its foundation is the clarification of the driving mechanisms of urban land expansion Previous studies have primarily focused on single large cities, with few explorations of the spatiotemporal differences in driving forces of ULSE of different towns in the same administrative region [18]. This study aims to fill this gap and focus on the small urban area or village scale.

Urban growth modeling aims to understand the dynamic processes, and therefore interpretability of models is becoming crucial. Interpretation of statistical models is desirable for gaining knowledge of the processes driving the change of spatial patterns [19].

\section{Land Change Modeler and Logistic Regression}

In this study, in order to detect, quantify and analyze the changes, post classification change analyses with ArcMap and 'Land Change Modeler' in IDRISI $®$ Selva have been employed [20], LCM module provides quantitative assessment of category-wise land use changes in terms of gains and losses with respect to each land use class [21].

The acquired data of the study area were processed and analyzed using GIS and Remote sensing techniques to obtain information for environmental and urban growth monitoring [20].

Empirical estimation models use statistical techniques to model the relationships between land use changes and the drivers based on historic data. As an empirical estimation method, logistical regression has been used in deforestation analysis [19].

Logistic regression analysis was conducted to reveal the relationship between urban growth and the driving factors of socioeconomic and biophysical factors [22] Logistic regression models are developed to derive a land use change probability surface [23].

Logistic regression analysis has been one of the most frequently utilized approaches during the past two decades for predictive land use modelling by means of variation of inductive modelling [24].

Regression is a method to discover the empirical relationships between a binary dependent and several independent categorical and continuous variables [24].

This paper applied logistic regression to model urban growth in study Area of Aswan in a GIS environment and to discover the relationship between urban growth and the driving forces.

This study discusses the major driving forces that led to urban sprawl and the value of effect of etch factors. Moreover, recommendations to resolve the conflicting interests of land and policy options are presented.

The aim of this paper is to study the driving forces of urban sprawl in study area and identify the effect level of this factors on urban area to prepare the data to the future work to expect the urban sprawl in future especially in risk area. 


\section{STUDY AREA}

The study area (Northern Abouelreesh village) is located in the province of Aswan, in southern Egypt. It lies between longitudes $32^{\circ} 52^{\prime} \mathrm{E}$ to $32^{\circ} 55^{\prime} \mathrm{E}$ and latitudes $24^{\circ} 10^{\prime} \mathrm{N}$ to $24^{\circ} 14^{\prime} \mathrm{N}$. The study area is bordered to the east by mountains and from the west by an agricultural region, and the River Nile. Fig. 1 shows the location of case study area location in relation to Egypt and the rest of the world.
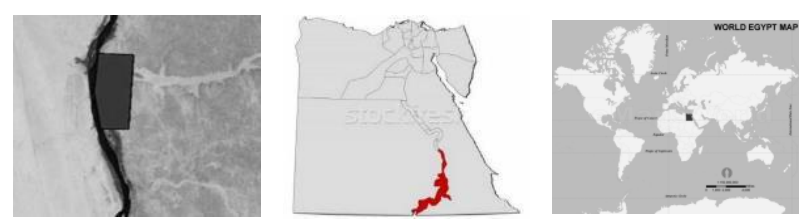

Fig. 1. The study area in relation to Egypt and the world.

The area of urban development approved for northern Abouelreesh in 2010 was approximately 453.01 acres. While roads, pathways and urban spaces occupied 106.11 acres, not the entire allocated area was suitable for urbanization. The designated area also encompassed within its boundaries land space for private property (about 67.33 acres), desert land (approximately 126.25 acres) and farmland (about 4.73 acres). The population of the village was about 9896 in 1986, rising to 12206 inhabitants in 1996 , then to 13189 in 2006 . The growth rate was $2.12 \%$ per annum in the period 1986-1996, decreasing to $0.78 \%$ per annum from 1996 to 2006 . The average population growth rate was $1.45 \%$ per annum from 1986 to 2006. The total population of the village in 2010 was about 14202 and the average family size was about 4.16 [25].

\section{RESEARCH METHODOLOGY AND DATA}

\section{A. Identifying the Urban Sprawl}

The research methodology in this section was aimed at studying the case study region in two periods of time in order to identify growth trends, especially in areas exposed to natural hazards. Fig 2. Shows the urban area in deferent year.

The official detailed plan for the study area was updating by using Google Earth to manually extract the relevant data to the year of building construction. This was followed by a visual analysis of high-resolution aerial images of the city in Google Earth.

Manual photointerpretation of high-resolution images in Google Earth was the key process in this mapping methodology. While manual image analysis might be the oldest form of remote sensing [16], the method described in this paper requires only personnel training in photointerpretation, minimal training (at most) in GIS, Internet access, and a computer with a relatively highresolution monitor.

\section{B. Chooseing the Driving Forces}

By reviewing related literature, it may be summarized that the driving forces of urban land use it is mainly include natural eco-environment, accessibility, socio-economic development, neighborhood factors, relevant planning and policies [18].
The research identify the driving factors from two sources, first one by reviewing related literature, [19] [22] [24] [23]. The second one by analyzed the official detailed plan and the experience of researcher with the study area after that using LCM's Test and selection of site and driver variable module was used to test the potential power of explanatory variables Only variables with values higher than 0.15 in Cramer's V Test were used.

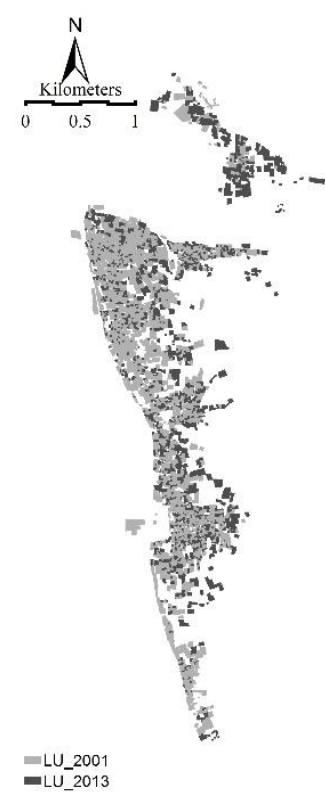

Fig. 2. Urban area in 2001 and 2013.

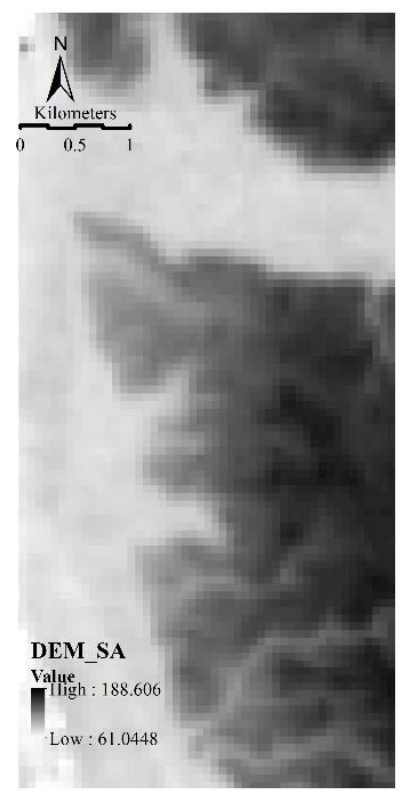

Fig. 3. Digital Elevation Model File for the case study area.
We have found the variables that have a Cramer's V of about 0.15 or higher are useful while those with values of 0.4 or higher are good [26]. Some of the determinants that were used in this study are shown in Table I. The driving factors in this study were divided in four groups: Accessibility, Planning and Policies, Services Buildings and Natural eco-environment.

\section{Land Use/Cover Change Modeler}

This study uses the Land Change Modeler for Ecological Sustainability. Land Change Modeler is an integrated software module in IDRISI®Selva that performs land change analysis, change prediction, and habitat and biodiversity impact assessment [27], Land use/cover change (LUCC) has become one of the key issues in global change research [18].

Use of such model also gives a better understanding of the functions of the land use systems and the support needed for planning and policy making. Such models can also predict the possible future change and use of the land cover under different scenario [26], [28].

Land Change Modeler (available in IDRISI®Selva or as an ARC-GIS extension) is based on Markov chain matrices and transition susceptibility maps obtained by logistic regression or by training learning machines [26] [29].

\section{Logistic Regression}

The dependent variable was prepared by processing the LUC 2001 and LUC 2013 using the Land Change Modeler (LCM) in IDRISI@Selva. The independent variables were prepared from the shape files of the driving factors by using 
ArcGIS.

TABLE I: CRAMER'S VALUE FOR VARIABLE

TABLE I: CRAMER'S VALUE FOR VARIABLE
\begin{tabular}{|l|c|}
\hline Variables & Cramer's V \\
\hline Accessibility & 0.6050 \\
\hline Distance to Main Roads & 0.2779 \\
\hline Distance to Regional Road & 0.3682 \\
\hline Distance to Railways Station & 0.4022 \\
\hline Planning and Policies & 0.3596 \\
\hline Proximity to Old Urban Area & 0.3096 \\
\hline Proximity to Nearby City (N. Aswan City) & 0.4073 \\
\hline Distance to Railways Foot cross & 0.4189 \\
\hline Services Buildings & 0.5302 \\
\hline Distance to Commercial & 0.4487 \\
\hline Distance to Educational & 0.4131 \\
\hline Distance to Religious & \\
\hline Distance to Social & 0.1795 \\
\hline Distance to Different Services & 0.0205 \\
\hline Natural eco-environment & 0.3687 \\
\hline Distance to Streams & \\
\hline Slope & Elevation \\
\hline
\end{tabular}

The raster layers for the independent variables were exported to IDRISI®Selva and used with the dependent variable in the logistic regression model that is available in the LCM [22].

The dependent variable in this model is a binary value representing the location of land use ( 0 if the land use is not present at the location, and 1 if the particular land use is present at the location) [23].

\section{E. Research Data}

Fulfillment of the research targets required detailed data. Unfortunately, the data available for the case study area were incomplete. For example, we could not conduct a proper analysis of the urban sprawl because the detailed plan from the government did not contain information on when the buildings in the urban areas were constructed. Secondly, there was the problem of low resolution files provided free online, for example, the DEM (Digital elevation models) files. High resolution DEM files were expensive to acquire.

Table II shows all data files used in simulation and their sources.

TABLE II: DATA USED IN THIS STUDY

\begin{tabular}{|c|c|}
\hline & Data Source \\
\hline Detailed plan & General Organization for Physical Planning - Aswan \\
\hline DEM file & U.S. Geological Survey ( USGS ) Website \\
\hline
\end{tabular}

Digital elevation models (DEM) as shown in Fig. 3 are an important source of information in GIS applications. The two most widely applied satellite-derived DEM datasets (SRTM and GDEM) were used in this study. SRTM provides near-global topographic coverage of the Earth's surface with a horizontal grid size of 3-arc-seconds ( $\sim 90 \mathrm{~m})$. As shown in Fig 3. Recently, 1-s $(30 \mathrm{~m})$ data for the whole world except the Middle East region were released [30]. Hazard assessments and inundation modelling of coastal areas rely heavily on both the accuracy and resolution of digital elevation models (DEMs) [31].

Owing to constraints faced in data collection, the methodology for this paper depended on the resolutions to the three problems mentioned. To overcome the first problem of incomplete information regarding the year of building construction, we used Google Earth historical images to obtain the necessary information. To resolve the second problem regarding the costs of obtaining high resolution imagery, we used the free online data despite their low resolution. We were able to obtain free DEM files.

\section{RUNNING MODEL}

\section{A. Change Analysis}

The Change Analysis tab provides a set of tools for the rapid assessment of change, allowing one to generate oneclick evaluations of gains and losses, net change, persistence and specific transitions both in map and graphical form. [26]

\section{1) LCM project parameters}

This panel allows for the specification of the essential files associated with the land cover change analysis of a specific study area. Some aspects of LCM can be used without specifying these files, most notably the species modeling and biodiversity modeling tools on the Implications tab. However, they are required for most elements of LCM [26].

For the change and prediction analyses, a minimum requirement is the specification of two land cover maps that can be used as the basis of understanding the nature of change in the study region and the means of establishing samples of transitions that should be modeled [26].

\section{2) Change analysis — land change modeler}

The Change Analysis panel provides three graphs of land cover change between the two land cover maps specified in the Project Parameters panel you can view these graphs in a variety of units (cells, hectares, square kilometers, acres, square miles, $\%$ of change and $\%$ of area). Note that changing the units on this panel causes the units on the Change Maps panel to also change, and vice versa. Fig 4. Shows the gains and losses between 2001 and 2013.

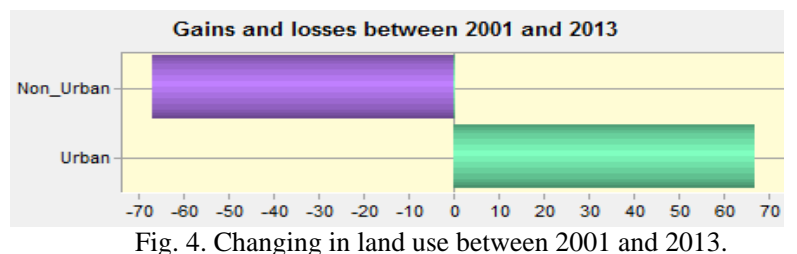

\section{3) Change maps - land change modeler}

This panel provides the ability to create a variety of change maps, including maps of persistence, gains and losses, transitions and exchanges. Note that changing the units on this panel causes the units on the Change Analysis panel to also change, and vice versa.

\section{4) Spatial trend of change - land change modeler}

In landscapes dominated by human intervention, patterns of change can be complex, and thus very difficult to decipher. This panel provides the ability to map trends with a best fit polynomial trend surface to the pattern of change. Trend of change for this model can be showed in Fig. 6. 


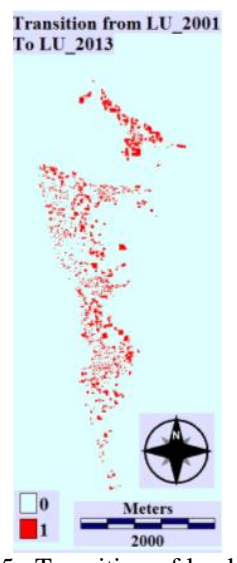

Fig. 5. Transition of land use.

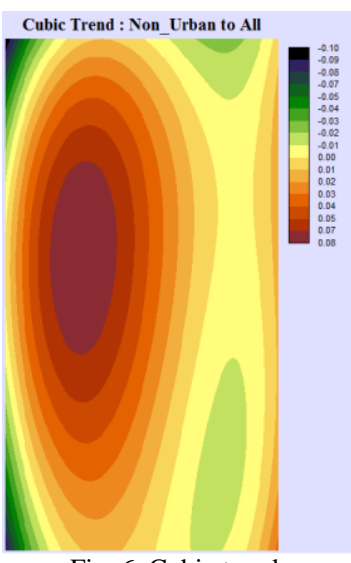

Fig. 6. Cubic trend

\section{B. Transition Potentials}

In order to predict change, we have to create a map of the potential of land showed in Fig 5. The Transition Potentials tab allows one to group transitions between two land cover maps into a set of sub-models resulting in a transition potential map for each transition an expression of timespecific potential for change.

\section{1) Transition sub-models: Status}

The table on this panel lists all transitions that exist between the two land cover maps (except those filtered out in the Change Analysis panel) and requires the user to specify which transitions are to be used for calculating the transition potentials.

\section{2) Variable transformation utility}

The Variable Transformation Utility panel is an optional panel for transition potential modeling that provides a selection of commonly used transformations. The transformations available include: natural log, exponential, logit, square root, power, and evidence likelihood.

These are particularly critical if the Logistic Regression modeling option is chosen since it requires that the variables be linearly related to the potential for transition. This research used the natural log to prepare the driving forces. Because the natural log transformation is commonly effective in linearizing distance decay variables.

\section{3) Test and selection of site and driver variables}

This is an optional panel that provides a quick test of the potential explanatory power of a variable. You must have specified a project in the Project Parameters panel before accessing these tools.

In general, we have found the variables that have a Cramer's V of about 0.15 or higher are useful while those with values of 0.4 or higher are good.

\section{4) Structure and run of transition sub-model}

The Run Transition Sub-Model panel is where the actual modeling of transition sub-models is implemented. This panel runs the transition sub-model specified in the Submodel to be evaluated combo box in the Transition SubModels: Status panel. This model undertakes binomial Logistic Regression and prediction using the Maximum Likelihood method.

\section{RESUlts}

The result of change analysis between 2001 and 2013 was gain 67 he from the urban area as urban sprawl in this period, this is area changed from non-urban area to urban area throw 12 years.

After transformed the driving forces file to natural log the research made very important step that was test and select the driver variables based on the Cramer's V factor. The Fig 7. Shows the driving variable.

From the table I. We can observe that all driver variables have Cramer's V more than 0.15 or higher this values are useful while those with values of 0.4 or higher are good. [26].

The research method excepted from the previews issues only one driver variable that was slope because this variable is very important to check its effective value in model while this study area has mountainous natural.

ROC (Relative Operating Characteristic) ROC is an excellent method to compare a Boolean map of "reality" versus a suitability map. Thus, ROC is included here as an excellent statistic for measuring the goodness of fit of logistic regression. The ROC value ranges from 0 to 1 , where 1 indicates a perfect fit and 0.5 indicates a random fit. [26]. The result of the ROC statistic was 0.9626 , which is a very strong value and indicates the soft prediction was very accurate.

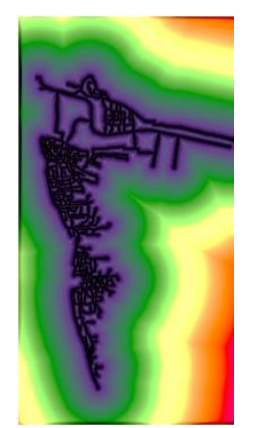

Dis. Main Roads
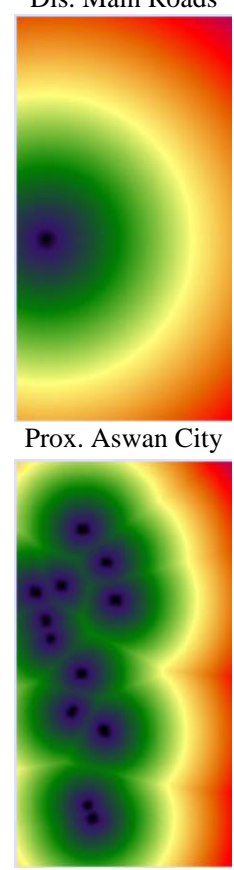

Dis. Educational

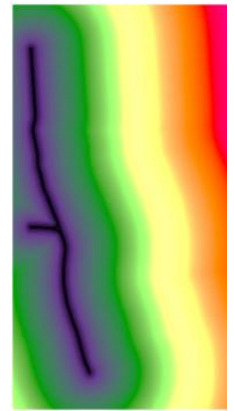

Dis. Regional Road

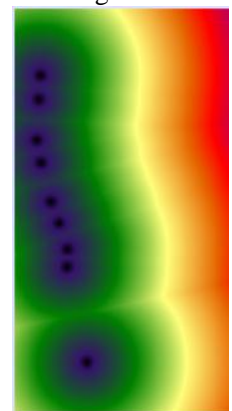

Dis. Rail. Foot cross

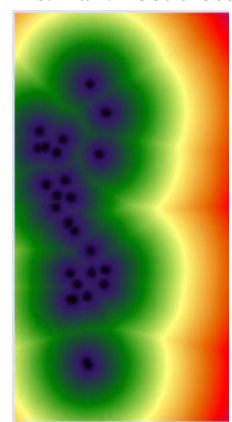

Dis. Religious

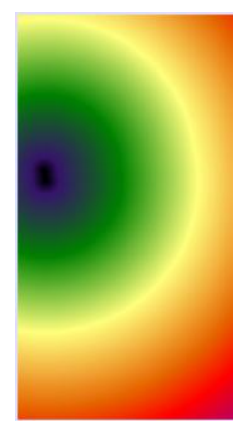

Dis. Railways Station
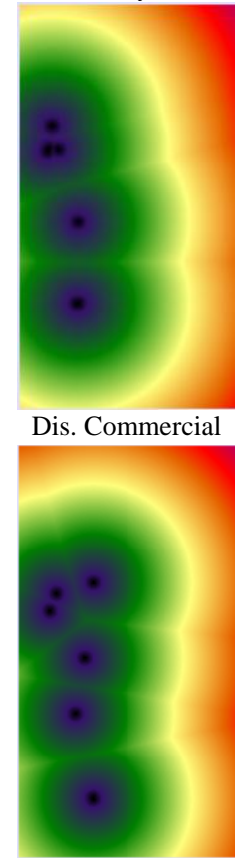

Dis. Social 


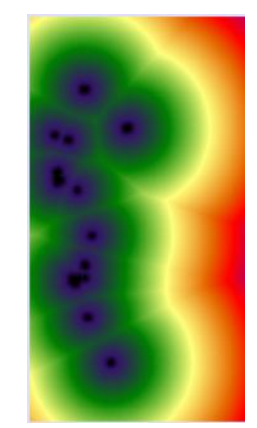

Dis. Different Services

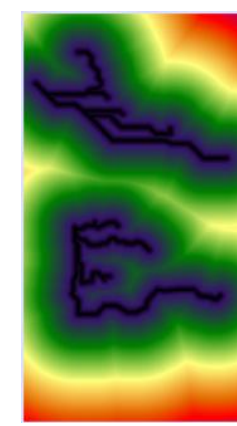

Dis. Streams Fig. 7. Driving factors

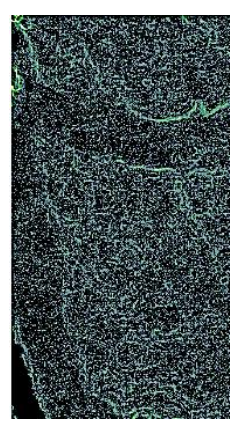

Slope
Using R2, or in our case the Pseudo R2, as a measure of goodness of fit for the logistic regression is questionable; in general, however, Thus, pseudo R2 $=1$ indicates a perfect fit, whereas pseudo R2 $=0$ indicates no relationship. Pseudo $\mathrm{R} 2$ greater than 0.2 is considered a relatively good fit. The result of pseudo $\mathrm{R} 2$ value is 0.3875 that is indicates a perfect fit.

The regression equation outputs the regression coefficients for each of the independent variables and the intercept. The intercept can be thought of as the value for the dependent variable when each of the independent variables takes on a value of zero. The coefficients indicate the effects of each of the independent variables on the dependent variable [26].

The parameter coefficients (positive or negative) in the equation are relative indicators of a positive or negative relationship between the probability and the independent variables. [26]

The correlation coefficient can vary from -1.0 (strong negative relationship) to 0 (no relationship) to +1.0 (strong positive relationship) [26].

As shown in Table III. , the evaluation of various factors' regression coefficient (b) for independent variables can be divided to two types, the first one based on the sign of coefficient relationship value was negative or positive, the second type was divided based on the category of variables.

\section{A. Sign Evaluation}

The first evaluation type is sign evaluation, as shown in Table III. all independent variables that has positive sign for coefficient indicate to positive relationship, if the value of independent variable increased the probability of urban growth will decrease, as selected in this study all independent variable test the distance to same driving forces except the slope an elevation, so that it can be conclude that whenever to be closer to the positive relationship factors the probability of urban growth will decreased especially when the value will be higher so that it can be consider the closing to this factor has a negative effect on urban growth, Only five factors has a positive coefficient, distance to Regional Road and old urban area has strong positive relationship while the distance to railway station, slope and elevation has very weak effect on urban growth because the coefficient for them was very small.

On other hand most of independent variables has negative coefficient that is indicate that whenever to be closer to the inverse relationship factors the probability of urban growth will increased and this factors will have attractive effect to urban sprawl, the most inverse relationship factors were
Distance to Religious and Proximity to Nearby City (N. Aswan City) the coefficient was -0.775 and -0.617 respectively, they have very strong effect to attract the urban sprawl, while Distance to Streams and Distance to Railways Foot cross had weak effect in attract on urban sprawl the coefficient was -0.092 and -0.136 respectively.

\section{B. Category Evaluation}

The first evaluation type is category evaluation, in this type can be evaluate the effect of etch categories based on the average of coefficient on it, as shown in table III. it can be observed that the most effective independent variables category was the services buildings, all factors in this group has the negative sign which mean inverse relationship between factors and urban sprawl with average of coefficient value about - 0.452 moreover the stronger factors was the Distance to Religious -0.775 and the most weak one was Distance to Educational -0.195.

The second category has most effective on urban sprawl was the Planning and Policies, this category has two strong factors Proximity to Old Urban Area and Proximity to Nearby City (N. Aswan City) and one has inverse relationship with weak value it was Distance to Railways Foot cross.

In addition Accessibility category has only one strong independent variables it was the Distance to Main Roads which has inverse relationship with strong value -0.423 while the other two independent variables was very weak.

The weakest effective category was the Natural ecoenvironment if can be neglect the sign we can found that the average of coefficient was 0.034 , this value has very weak effect in urban sprawl even the sign was negative or positive.

TABLE III: COEFFICIENT VALUE FOR VARIABLE

\begin{tabular}{|l|c|}
\hline Variables & Coefficient \\
\hline Accessibility & -0.42303725 \\
\hline Distance to Main Roads & -0.05626237 \\
\hline Distance to Regional Road & 0.00185688 \\
\hline Distance to Railways Station & 0.55026085 \\
\hline Planning and Policies & -0.61736236 \\
\hline Proximity to Old Urban Area & -0.13624385 \\
\hline Proximity to Nearby City (N. Aswan City) & -0.59813874 \\
\hline Distance to Railways Foot cross & -0.19507816 \\
\hline Services Buildings & -0.77570819 \\
\hline Distance to Commercial & -0.24063162 \\
\hline Distance to Educational & -0.44598478 \\
\hline Distance to Religious & -0.09207333 \\
\hline Distance to Social & 0.00147021 \\
\hline Distance to Different Services & 0.00976199 \\
\hline Natural eco-environment &
\end{tabular}

\section{CONCLUSION}

Identify the driving factors that can led the urban sprawl is very useful method to try understanding the expansion of urban area, and helping the decision-makers and planners to expect the urban growth in future.

Urban growth in Abouelreesh had been effected by several factors some of them had positive relationship such as Proximity to Old Urban Area that has the stronger 
positive relationship with urban sprawl and unattractive factors in urban area.

While the most attractive driving factors in study area was Distance to Religious, this factor has inverse relationship that mean the high probability to urban growth when the distance with it will be short.

We recommend that a field survey be undertaken first to identify the old urban areas. After this, a comparison can be made between the field observations and manual photointerpretation from satellite imagery obtained from Google Earth. This would give a good indication of the urban sprawl. At the same time, the discrepancies between the two methods would help researchers calibrate the manual photo-interpretation that can be used to obtain a rapid result without cost.

\section{REFERENCES}

[1] Vaz and P. Nijkamp, "Gravitational forces in the spatial impacts of urban sprawl: An investigation of the region of Veneto, Italy," Habitat International, 2015.

[2] L. Jiao, "Urban land density function: A new method to characterize urban expansion," Landscape and Urban Planning, 2015.

[3] Belal, "Detecting urban growth using remote sensing and GIS techniques in Al Gharbiya governorate, Egypt," Elsevier, 2011.

[4] N. M. Noor, "Determination of spatial factors in measuring urban sprawl in Kuantan using remote sensing and GIS," in Proc. ASEAN Conference on Environment-Behaviour Studies, Hanoi, Vietnam, 2013.

[5] W. Yue, Y. Liu, and P. Fan, "Measuring urban sprawl and its drivers in large Chinese cities: The case of Hangzhou," Land Use Policy, 2013.

[6] Lagarias, "Urban sprawl simulation linking macro-scale processes to micro-dynamics through cellular automata, an application in Thessaloniki, Greece," Applied Geography, 2012.

[7] C. Couch and J. Karecha, "Controlling urban sprawl: Some experiences from Liverpool," Cities, 2006.

[8] M. M. Amin Abd-Allah, "Modelling urban dynamics using geographic information systems, remote sensing and urban growth models," Cairo, 2007.

[9] R. Hegazy and M. R. Kaloop, "Monitoring urban growth and land use change detection with GIS and remote sensing techniques in Daqahlia governorate Egypt," International Journal of Sustainable Built Environment, 2015.

[10] Shalaby, "Assessment of urban sprawl impact on the agricultural land in the Nile delta of Egypt using remote sensing and digital soil map," International Journal of Environmental Sciences, 2012.

[11] P. David, "Horizontal positional accuracy of Google earth's highresolution imagery archive," Sensors, 2008

[12] L. C. Matthew and M. A. T., "Virtual interpretation of earth webinterface tool (VIEW-IT) for collecting land-use/land-cover reference data," Remote Sensing, 2011.

[13] J. Faith and Y. Danlin, "Spatial distribution of greenhouse commercial horticulture in Kenya and the role of demographic, infrastructure and Topo-Edaphic factors," International Journal of Geo-Information, 2014.

[14] T. Dawn, "Analyzing wildlife habitat with Google earth," Green Teacher, vol. 87, 2009.

[15] R. W. Courtney, M. James, M. T. Nancy, and G. M. James, "From local to global: A birds-eye view of changing landscapes," The American Biology Teacher, 2010.
[16] R. T. John and T. L. Sarah, "Mapping public and private spaces of urban agriculture in Chicago through the analysis of high-resolution aerial images in Google Earth," Landscape and Urban Planning, 2012.

[17] C. Antoine, N. Kazuo, and N. Takashi, "Mapping VHR water depth, seabed and land cover using Google earth data," International Journal of Geo-Information, 2014.

[18] B. Shu, H. Zhang, and Y. Li, "Spatiotemporal variation analysis of driving forces of urban land spatial expansion using logistic regression: A case study of port towns in Taicang City, China," Habitat International, 2014.

[19] Z. Hu and C. Lo, "Modeling urban growth in Atlanta using logistic regression," Computers, Environment and Urban Systems, 2007.

[20] M. G. Tewolde and P. Cabral, "Urban sprawl analysis and modeling in Asmara, Eritrea," Remote Sensing, 2011.

[21] T. Ramachandra, H. B. Aithal, and S. Vinay, "Modelling urban revolution in greater Bangalore, India," in Proc. 30th Annual InHouse Symposium on Space Science and Technology, Bangalore, 2013.

[22] A. S. Hasyim and B. Dahlan, "Modeling of urban growth in tsunamiprone city using logistic regression: Analysis of Banda Aceh, Indonesia," Applied Geography, 2015.

[23] T. Munshi, M. Zuidgeest, and M. Brussel, "Logistic regression and cellular automata-based modelling of retail, commercial and residential development in the city of Ahmedabad, India," Cities, 2014.

[24] J. J. Arsanjani, M. Helbich, and W. Kainz, "Integration of logistic regression, Markov chain and cellular automata models to simulate urban expansion," International Journal of Applied Earth Observation and Geoinformation, 2013.

[25] G. O. O. P. P. Gopp, "Detailed planning for the village of Abu Rish North - Aswan Governorate," Cairo, 2010.

[26] J. R. Eastman, The Idrisi Selva Help, Clark Labs, Clark University, 2012.

[27] L. Lin, E. Sills, and H. Cheshire, "Targeting areas for reducing emissions from deforestation and forest degradation (REDD+) projects in Tanzania," Global Environmental Change, 2014.

[28] V. N. Mishra, P. K. Rai, and K. Mohan, "Prediction of land use changes based on land change modeler (lcm) using remote sensing: A case study of muzaffarpur (bihar), India," Geographical Institute Jovan Cvijic, 2014.

[29] J.-F. Mas, M. Kolb, and M. Paegelow, "Inductive pattern-based land use/cover change models: A comparison of four software packages," Environmental Modelling and Software, 2014.

[30] A. J. Abdollah, N. C. John, R. M. Tim, G. V. N. Thomas, and R. L. Joshua, "Satellite-derived digital elevation model (DEM) selection, preparation and correction for hydrodynamic modelling in large, lowgradient and data-sparse catchments," Journal of Hydrology, 2015.

[31] S. Christopher and S. Robert, "Correlation scales of digital elevation models in developed coastal environments," Remote Sensing of Environment, 2015.

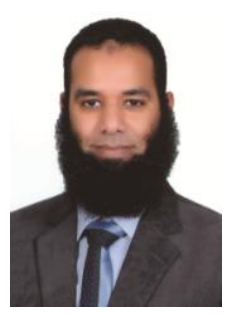

Omar Hamdy was born in Egypt in October 1981 $\mathrm{He}$ is currently doing his $\mathrm{PhD}$ study at Kyushu University, Fukuoka, Japan. He finished his masters from South Valley University, Egypt in 2009.

His research interests include urban growth, Urban planning, risk management and natural disaster.

He was a member in a tempus project in Aswan Faculty of Engineering (Virtual Laboratories Developing Center; a (SIQ@CEP) project a sustainable improvement and qualifying system for accreditation for civil engineering program in Aswan Faculty of Engineering. He is a research project entitled as "Medium and small sized towns extrusive development methodology in the south upper Egypt" 